\title{
Purification and cloning of glyoxalase II from rat liver
}

\author{
Mi Young Cho, ${ }^{1}$ Chang-Dae Bae, ${ }^{1}$ \\ Jae-Bong Park ${ }^{1}$ and Tong-Ho Lee ${ }^{1,2}$ \\ 1 Department of Biochemistry, Medical College, Hallym University \\ 2 Corresponding author \\ Accepted 20 March 1998
}

Abbreviations: CBG, carbobenzoxyglutathione; GLO, glyoxalase; MGO, methylglyoxal; PMSF, phenylmethylsulfonyl fluoride; S-LG, S-lactoylglutathione describe the purification of GLO II from rat liver by two step procedures, determination of $\mathrm{N}$-terminal 9 amino acids sequence of GLO II and cloning of its CDNA.

\section{Materials and Methods}

\section{Synthesis of carbobenzoxyglutathione}

As an affinity ligand, carbobenzoxyglutathione (CBG), a strong inhibitor of GLO II, was prepared from carbobenzoxy chloride (ICN) and GSH according to the method described by Norton and Hsu (1983) and purified by silica gel TLC (Sigma). The purified CBG was then coupled to activated $\mathrm{CH}$ Sepharose 4B (Pharmacia).

\section{Purification of GLO II}

Rat (Sprague Dawley) liver (3.7 g) was homogenized in $0.25 \mathrm{M}$ sucrose containing $2 \mathrm{mM}$ 2-mercaptoethanol and the homogenate was subjected on a Affigel blue column $(2.5 \times 17.5 \mathrm{~cm})$ preequilibriated with $40 \mathrm{mM}$ phosphate buffer, $\mathrm{pH} 7.2$, containing $2 \mathrm{mM}$ 2-mercaptoethanol and $0.1 \mathrm{mM}$ phenylmethylsulfonyl fluoride (PMSF). The column was washed with the buffer to remove the unabsorbed substances and eluted with the buffer containing 0 to 0.5 $\mathrm{M} \mathrm{KCl}$ gradient. The fraction from the Affigel column was subjected to a CBG-Sepharose column $(1.5 \times 8 \mathrm{~cm})$ equilibriated with a mixture of the phosphate buffer: glycerol $(9: 1)$. The protein was eluted using a gradient of 0 to $3 \mathrm{M} \mathrm{KCl}$.

\section{Assay for GLO II activity}

The activity of GLO II was analyzed according to the method described by Uolita (1973) or Principato et al. (1987). One unit of the activity was defined as the amount of enzyme catalyzing the hydrolysis of $1 \mu \mathrm{mol}$ of S-LG/ min or the formation of $1 \mu \mathrm{mol}$ of 5,5'-dithiobis-(2-nitrobenzoic acid)/min using molar absorption coefficient $3,310 \mathrm{~cm}^{-1}$ at $240 \mathrm{~nm}$ or $13,600 \mathrm{~cm}^{-1}$ at $412 \mathrm{~nm}$.

\section{SDS-PAGE}

SDS-PAGE was carried out using $12 \%$ gel according to the method of Laemmi (1970). After electrophoresis the gel was stained with Coomassie Brilliant Blue R 250 or subjected to Western blotting with rabbit anti-bovine liver GLO II prepared previousely in this laboratory (Yang et al., 1995) as a primary antibody and horseradish peroxidaseconjugated anti-rabbit by immunoglobulin (Amersham) as a secondary antibody. Signal was detected by using ECL reagents (Amersham). 


\section{Determination of amino acid sequence}

The purified GLO II $(0.5 \mu \mathrm{g})$ was subjected to SDS-PAGE (12\% gel) using Tricine SDS running buffer. Protein on the gel was electrotransfered to PVDF membrane and the protein band corresponding to GLO II after Coomassie Brilliant Blue staining was excised. After removing $\mathrm{N}$ acetyl blocking group of amino terminal with $1 \mathrm{M} \mathrm{HCl}$ at $110^{\circ} \mathrm{C}$ for $1 \mathrm{~h}$, the protein was subjected to Edman degradation using Beckman LF 3500 gas phase amino acid sequencer. Phenylthiohydantoin derivative after each cycle was analyzed by HPLC.

\section{Cloning of GLO II}

\section{Primer}

Two degenerative primers, RG-N1 and RG-N2 with 24 base size corresponding to $\mathrm{N}$-terminal region, were synthesized and used as primary primer as well as oligo$p(d T){ }_{15}$. The secondary primers, RG-N1A and RG-C1A were synthesized from internal sequences after partial sequencing.

\section{Isolation of RNA and synthesis of first strand cDNA}

Whole RNA from rat liver $(0.5 \mathrm{~g})$ was isolated by routine method. First strand cDNA was synthesized using cDNA synthesis kit (Boehringer Mannheim) in $20 \mu \mathrm{l}$ reaction mixture containing $5 \mathrm{mM} \mathrm{MgCl}_{2}, 1 \mathrm{mM}$ deoxynucletide mixture, $1.6 \mu \mathrm{g}$ oligo-p(dT), gelatin $4 \mathrm{ng}$, RNase inhibiors 50 units, AMV reverse transcriptase 20 units and $20 \mu \mathrm{g}$ of the isolated RNA.

\section{PCR}

For PCR amplification, $1 \mu \mathrm{g}$ of first strand cDNA was added in a $20 \mu \mathrm{l}$ PCR reaction mixture with $10 \mathrm{mM}$ Tris$\mathrm{HCl}, \mathrm{pH} 8.3,1.5 \mathrm{mM} \mathrm{MgCl}_{2}, 50 \mathrm{mM} \mathrm{KCl}, 0.4 \mathrm{mM}$ of each dNTP, $0.4 \mu \mathrm{M} 5^{\prime}$ and $3^{\prime}$ primers, and 0.5 units Taq polymerase. Nonspecific PCR amplification was performed 3 cycles at $95^{\circ} \mathrm{C}$ for $30 \mathrm{sec}$ for denaturation, at $45^{\circ} \mathrm{C}$ for $1 \mathrm{~min}$ for annealing, at $72^{\circ} \mathrm{C}$ for $1 \mathrm{~min}$ for extension and then specific amplification was carried out 40 cycles at $95^{\circ} \mathrm{C}$ for $30 \mathrm{sec}$ for denaturation, at $55^{\circ} \mathrm{C}$ for $1 \mathrm{~min}$ for annealing and at $72^{\circ} \mathrm{C}$ for $1 \mathrm{~min}$ for extension.

\section{Cloning of PCR product}

After purification of DNA from PCR product by $1 \%$ LMT agarose gel electrophoresis using QIAEX II kit (Qiagen), the purified DNA was ligated to PT7 blue vector (Novagen). Competent cells were transformed with the ligated vector and incubated in amphicillin-LB-agar plate containing X-Gal and IPTG (Gibco/BRL).

\section{Base sequence analysis}

After purification of plasmid from the transformant DNA sequence was analyzed by Sanger's dideoxy method using Delta-Taq cycle sequencing kit (USB) by following the manufacturer's instructions.

In addition to the methods described above GLO II gene cloning using cDNA library of rat liver (Clontech) as starting material was also carried out by library screening according to the method described in Clontech lamda library protocol.

\section{Results and Discussion}

\section{Purification of GLO II}

After Affigel blue (Figure 1) and CBG affinity (Figure 2) chromatography of rat liver homogenate, GLO II was purified 1488 fold with $21 \%$ yield (Table 1 ), showing that the two steps of affinity chromatography are highly efficient method for GLO II purification. The purified preparation gave a single band at the position corresponding to 29 $\mathrm{kDa}$ on SDS-PAGE (Figure $3 \mathrm{~A}$ ) and the same band reacted with rabbit anti-bovine liver GLO II (Figure 3B), suggesting a high homology between rat and bovine GLO II. The presence of a single band of the GLO showing SDS-PAGE suggests that there is no polymorphism in rat liver GLO II.

\section{$\mathrm{N}$-terminal amino acid sequence}

The N-terminal amino acid sequence of rat liver GLO II

Table 1. Purification of GLO II from rat liver.Fresh rat liver $(3.7 \mathrm{~g})$ was homogenized. Homogenate was chromatographed on Affigel blue column $(2.5 \times 17.5 \mathrm{~cm})$ and then CBG-Sepharose column $(1.5 \times 8 \mathrm{~cm})$. The GLO II activity was determined using S-LG as substrate.

\begin{tabular}{lcccccc}
\hline \multicolumn{1}{c}{ Step } & $\begin{array}{c}\text { Vol. } \\
(\mathrm{ml})\end{array}$ & $\begin{array}{c}\text { Total activity } \\
\text { (units) }\end{array}$ & $\begin{array}{c}\text { Total protein } \\
(\mathrm{mg})\end{array}$ & $\begin{array}{c}\text { Specific activity } \\
(\text { units } / \mathrm{mg})\end{array}$ & $\begin{array}{c}\text { Fold } \\
\text { Yield } \\
(\%)\end{array}$ \\
\hline $\begin{array}{l}\text { Homogenate } \\
\begin{array}{l}\text { Affi-gel blue } \\
\text { chromatography }\end{array}\end{array}$ & 16 & 97.07 & 287.84 & 0.34 & 1.0 & 100 \\
$\begin{array}{l}\text { CBG affinity } \\
\text { chromatography }\end{array}$ & 222 & 55.08 & 47.74 & 1.154 & 3.4 & 57 \\
\hline
\end{tabular}




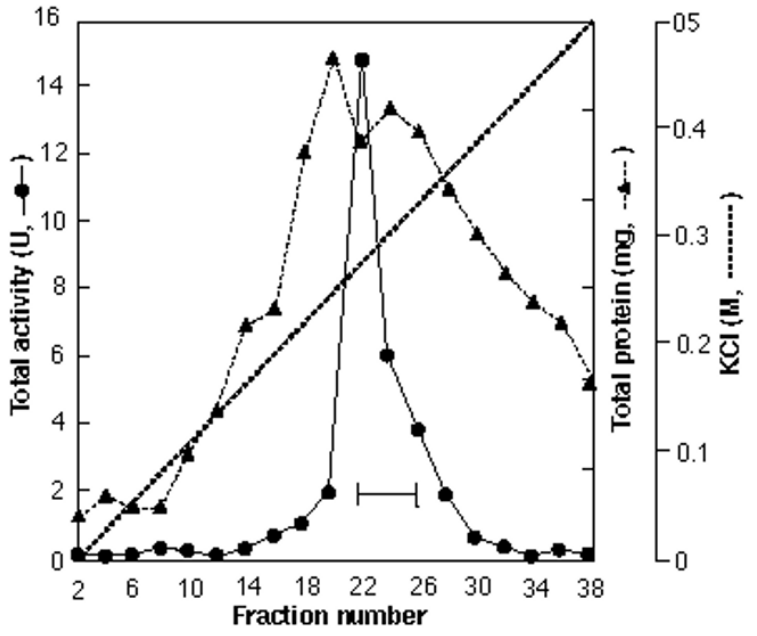

Figure 1. The profile of Affigel blue chromatography. Rat liver homogenate was applied to Affigel column $(2.5 \times 17.5 \mathrm{~cm})$ equilibriated with $40 \mathrm{mM}$ potassium phosphate, $\mathrm{pH}$ 7.2 containing $2 \mathrm{mM}$ 2-mercaptoethanol and $0.1 \mathrm{mM}$ PMSF. The column was washed with $270 \mathrm{ml}$ of the buffer. The column was then eluted with a gradient of $0-0.5 \mathrm{M} \mathrm{KCl}$ in $400 \mathrm{ml}$ of the same buffer and fractions indicated with bar were pooled.
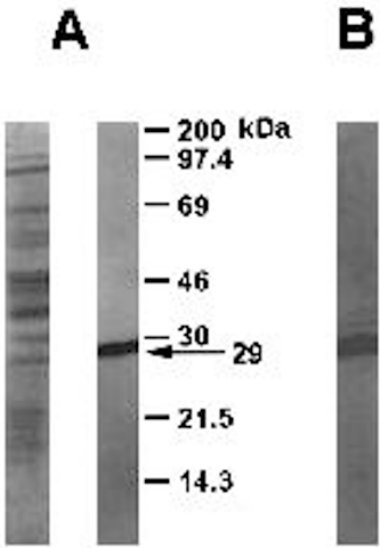

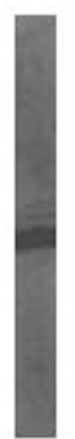

Figure 3. SDS-PAGE of purified GLO II. A. Coomassie Brilliant Blue R 250 staining: lane 1, rat liver whole homogenate; lane 2, purified GLO II. B. Western blot analysis of purified GLO II. Anti-GLO II antibody and peroxidase-conjugated anti-rabbit IgG were used as primary and secondary antibody, respectively. Signal was shown by using ECL reagents.

was determined by 10 cycles of Edman degradation and HPLC. The sequence of $\mathrm{N}$-terminal 9 amino acid residues was Met-Glu-Ile-Arg-Leu-Leu-Pro-Ala-Thr. Recently, Ridderström et al. (1996) has reported the whole amino acid sequence of human liver GLO II. When the Nterminal 9 amino acid sequence of rat liver GLO II was compared with that of human liver GLO II, it showed deletion of one amino acid residue at position 9 and $50 \%$ homology i.e. substitutions are seen at residues 2 ,

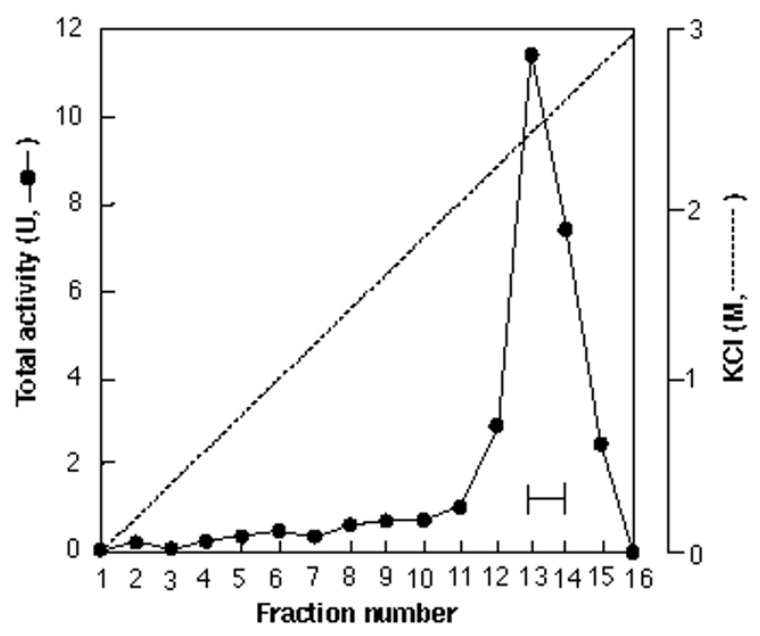

Figure 2. The profile of CBG affinity chromatography. Partially purified GLO II was loaded onto CBG-Sepharose 4B column $(1.5 \times 8 \mathrm{~cm})$ equilibriated with buffer $(9$ parts of $40 \mathrm{mM}$ potassium phosphate, $\mathrm{pH} 7.2$, containing $2 \mathrm{mM}$ 2-mercaptoethanol and 0.1 mM PMSF : 1 part of glycerol). The column was washed with the buffer and then eluted with a gradient of $0-3 \mathrm{M} \mathrm{KCl}$ in $80 \mathrm{ml}$ of the same buffer and fractions indicated with bar were pooled.

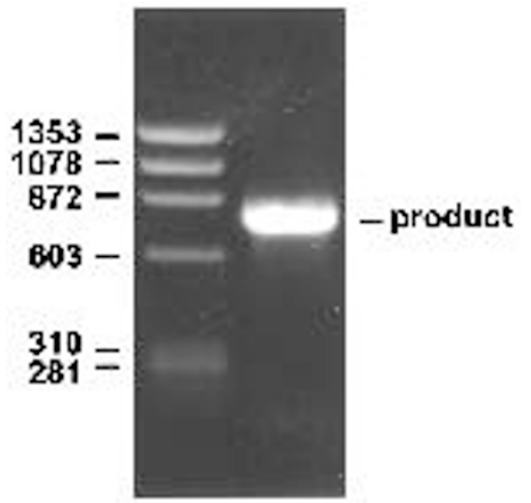

Figure 4. Agarose gel electrophoresis of PCR products with primers RG-N1, RG-N2 and oligo-p(dT) 15 .

\section{3, 4 and 5 (Table 2).}

\section{Cloning of GLO II}

The sequences of two degenerative primers, RG-N1 and RG-N2, synthesized from the amino acid sequence of $\mathrm{N}$-terminal region and two internal primers of RG-N1A and $-\mathrm{C} 1 \mathrm{~A}$ obtained from the partial sequence are shown in Table 3.

Electrophoretic pattern of the isolated RNA from rat liver showed clearly two ribosomal $28 S$ and $18 S$ RNA bands, suggesting that RNA extraction was achieved without degradation (data not shown). First strand cDNA was obtained from whole RNA by AMV reverse transcriptase and was amplified by PCR using RG-N1, -N2 


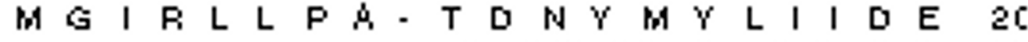

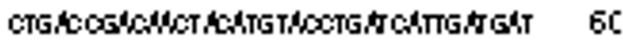

D T Q E \& A V W D P V Q P Q K V I E T V 40

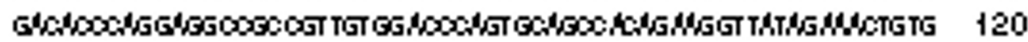

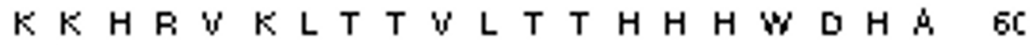

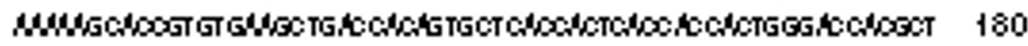

G GNEKLWKLEPG LKV V G G D D 80

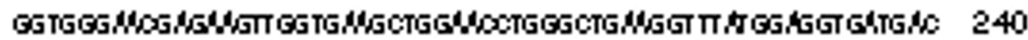

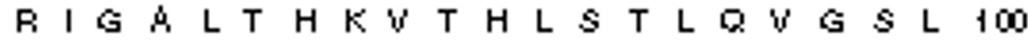

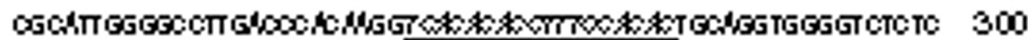

$S V K \& L S T P \& H T S G H I \& Y P V S 120$

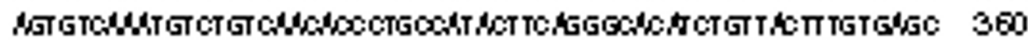

$K F G S S E P S A$ S $F$ T G D T L F W G 140

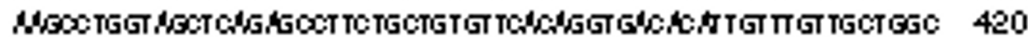

C G K F Y E G T A D E W K K L L E V L 160

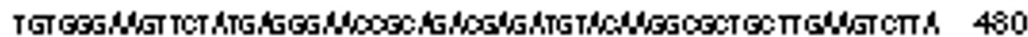

G R L P P D T K V V C G H E V T V N N L 180

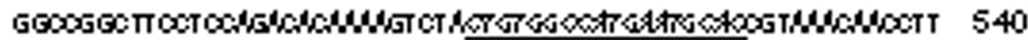

KF A R H W E F G N A V Q EKL A W A 200

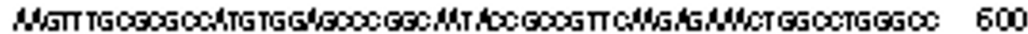

K E K N A I G E P T V P S T L A E E F T 220

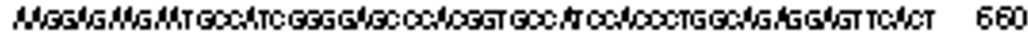

$\checkmark N P F M T V K E K T$ W $Y$ Q

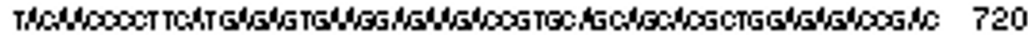

$P$ V T T M R A I R R E K D

253

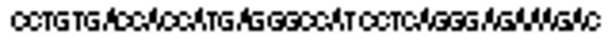

Figure 5. Nucleotide sequence of cDNA and the deduced amino acid sequence of GLO II from rat liver. Amino acid sequence of $\mathrm{N}$-terminal region was directly determined from purified GLO II. Base sequences indicated with underlined Italic were used as secondary primers. The sequence of $\mathrm{C}$-terminal region was failed to be determined in this study.
Table 2. N-terminal amino acid sequence of rat liver GLO ॥

\begin{tabular}{llllllllllll}
\hline Rat & $M$ & $G$ & I & R & $L$ & $L$ & $P$ & $A$ & - & $T$ \\
Human $^{1}$ & $M$ & $K$ & $V$ & $E$ & $V$ & $L$ & $P$ & $A$ & $L$ & $T$ \\
\hline
\end{tabular}

${ }^{1}$ Cited from Ridderström et al. (1996)

Table 3. Primers used for PCR.

\begin{tabular}{|c|c|}
\hline $\mathrm{RG}-\mathrm{N} 1^{1}$ & ATGGGTATCGAGCTGCTGCCGGCG \\
\hline RG-N2 ${ }^{1}$ & ATGGGCATTGAACTCCTCCCAGCT \\
\hline$R G-N 1 A^{2}$ & TCACACACCTTTCCACAC \\
\hline$R G-C 1 A^{2}$ & GTGTATTCATGGCCACAG \\
\hline
\end{tabular}

${ }^{1}$ Primary degenerative primers synthesized from the $\mathrm{N}$-terminal amino acid sequence.

${ }^{2}$ Secondary primers synthesized after partial base sequencing. and oligo-p $(\mathrm{dT})_{15}$ primers. The resulting PCR product showed a band of GLO II cDNA with 800-900 base pairs (Figure 4). After the ligation of the obtained GLO II cDNA with pT7 blue vector and transformation of competent cells with the ligated product, the cloned GLO II cDNA was obtained and subjected to the second PCR. From sequence analysis of the first PCR product, the sequences of about 300 base pair length of $5^{\prime}$ and $3^{\prime}$ regions were determined. As shown in Figure 5, 735 base pair sequence out of entire GLO II cDNA was determined using internal primers, RG-N1A and RG-C1A, obtained from partial sequence. Considering the $\mathrm{N}$-terminal 9 amino acid sequences (shown in Table 2) and full base sequence of human GLO II (783 base pair), the sequence of 5 '- end with 24 bases corresponding the $\mathrm{N}$-terminal region and 3 '-end with about 24 bases were failed to be determined directly in this study. Cloning by library screening using 
cDNA library gene showed the same result.

Entire amino acid sequence of rat liver GLO II deduced from the base sequence including the $\mathrm{N}$-terminal region of nine amino acids which were determined by Edman degradation (see Table 2) is presented in Figure 5.

GLO II cDNAs from human and Arabidopsis thaliana have recently been cloned and sequenced (Ridderström et al., 1996; Ridderström and Mannervik, 1997). Comparison of the two cDNA nucleotide and amino acid sequences deduced from the cDNA sequences shows $60 \%$ and $54 \%$ identity, respectively and certain limited regions shares $100 \%$ identity, indicating that they are derived from the same ancester. However, their entire sequences are quite divergent, reflecting their evolutional distance.

Comparison of rat GLO II cDNA and amino acid sequence obtained in this study with those from human demonstrated $87 \%$ and $90 \%$ identity, respectively. Particularly, two segments $45-70$ and $130-152$ of rat GLO II were $100 \%$ identical with corresponding sequences in the human enzyme. The higher homology in nucleotide and amino acid sequence of GLO II between human and rat than between human and plant is well in accord with their evolutional closeness.

The first identical region 45-70 contains four histidine residues. On considering that histidine residue is involved in the catalytic acivity of the enzyme (Ball and Vander Jagt, 1981), the region seems to be important in the activity. Analysis of the three-dimensional structure from the deduced amino acid sequence using protein analysis program of Macvector showed that the region 45-70 is buried in the protein to form the active site pocket. The domain also had partial flexibility, which may have the advantage for being used as the active site. These analyses support the assumption that the region is participated in the enzyme activity (data not shown).

Although this study provides a little understanding on the primary structure and active site of GLO II, further molecular biological studies using the cloned GLO II cDNA is remained to be done to elucidate the biological role and catalytic mechanism of the enzyme.

\section{Acknowledgement}

This work was supported by a grant from the Ministry of Education for Basic Medical Science Research, Korea, 1995.

\section{References}

Ball, J. C. and Vander Jagt, D. L. (1981) S-2-hydroxyacylglutathione hydrolase (glyoxalase II): active site mapping of a nonserine thiolesterase. Biochemistry 20: 899905

Laemmli, U. K. (1970) Cleavage of structural proteins during the assembly of the head of bacteriophage T4. Nature 15: 227(259): 680-685

Mannervik, B. (1980) Glyoxalase I. In Enzymatic Basis of Detoxification, pp. 263-293, Academic Press, New York

Norton, S. J. and Hsu, Y. R. (1983) S-Carbobenzoxyglutathione: A competitive inhibitor of mammalian glyoxalase II. J. Med. Chem. 26: 1784-1785

Principato, G. B., Rosi, G., Talsa, V. and Giovannini, E. (1987) Purifica-tion and characterization of two forms of glyoxalase II from the liver and brain of Wistar rats. Biochem. Biophys. Acta 911: 349-355

Racker, E. (1951) The mechanism of action of glyoxalase. J. Biol. Chem. 190: 685-696

Ridderström, M. and Mannervick, B. (1997) Molecular cloning and charac-terization of the thiolesterase glyoxalase II from Arabidopsis thaliana. Biochem. J. 322: 449-454

Ridderström, M., Mannervik, B., Saccucci, F., Hellman, U., Bergman, T. and Principato, G. (1996) Molecular cloning, heterologous expression and characterization of human glyoxalase II. J. Biol. chem. 271: 319-323

Thornalley, P. J. (1990) The glyoxalase system: new developments towards functional characterization of a metabolic pathway fundamental to biological life. Biochem. J. 269: $1-11$

Thornalley, P. J. (1993) The glyoxalase symtem in health and disease. Mol. Aspects. Med. 14(4): 287-371

Uotila, L. (1973) Purification and characterization of S-2-hydroxyacyl-glutathione hydrolase (glyoxalase II) from human liver. Biochemistry 12: 3944-3951

Yang, J. U., Bae, C. D., Park, J. B. and Lee, T. H. (1995) Purification and characterization of glyoxalase II from bovine liver. Korean J. Biochem. 27: 99-103 